animals has been studied and are now being upgraded for production of their 'long life' milk by selective breeding.

With present population pressures on land in Europe and Africa, the only hope for the remaining large mammals is conservation through utilisation; and this implies the substitution of biology for tradition in food and agricultural policies.

\title{
Iran Guards its Wildlife
}

The great care and interest that Iran takes in her wildlife is evident in Conservation and Wildlife Management in Iran, by Eskandar Firouz, published by the Iran Game and Fish Department, an excellent, informative and well illustrated booklet. Nearly every major habitat of this vast country is represented in the seven wildlife parks and thirty protected regions, covering some ten million acres.

The story of the extremely rare Persian fallow deer is typical. Believed to be extinct in 1940, when two small pooulations were discovered in south-west Iran in 1955 the area was given Protected Region status, and is now estimated to hold at least 40 animals. Some were sent to Dr Georg von Opel in Germany to build up a captive breeding herd (which now numbers 16 pure-bred animals) and a new park was created on land presented by HIH Prince Abdorreza, where, after considerable difficulties, a herd has been built up to at least 17 animals.

With the Persian wild ass, the onager, which had been hunted almost to vanishing point, protection of the herds and preservation of the habitat have permitted a dramatic increase, and numbers are now put at a minimum of 1200 animals. The cheetah, thanks to successful management of its prey species, such as the gazelle, is holding its own in the eastern deserts and numbers may exceed 200.

The creation in 1971 of the Buhu Kalat Protected Region should give the marsh crocodile the chance to build up its very low numbers.

YOUNG MARAL STAG, a race of the red deer found in Asia Minor, the Caucusus and northern Iran -

Eskandar Firouz

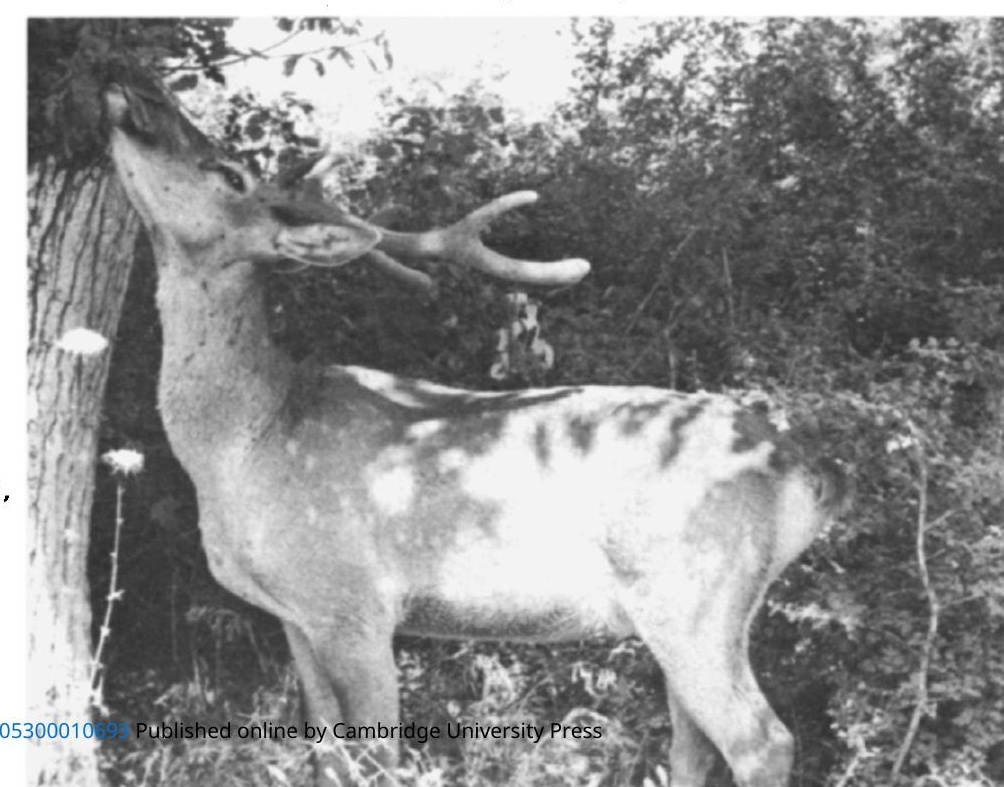

